\title{
PERTURBATION BOUNDS FOR CERTAIN OPERATOR FUNCTIONS
}

\author{
JASPAL SINGH AUJLA
}

\begin{abstract}
Some inequalities for norms and spectral radius involving operator monotone functions have been obtained. Lieb's concavity for trace of certain function has also been considered in general form.
\end{abstract}

Mathematics subject classification (2000): 47A30, 47B15, 15A60.

Key words and phrases: Positive operator, operator monotone function, unitarily invariant norm.

\section{REFERENCES}

[1] T. ANDO, Topics on operator inequalities, Lecture notes, Hokkaido University, Sapporro, 1987.

[2] H. ARAKI, On an inequality of Lieb and Thirring, Letters in Math. Phys. 19 (1990), 167-170.

[3] J. S. Aujla AND H. L. VASUdEVA, Some convex and monotone matrix functions, Linear Alg. Appl. 248 (1996), 47-60.

[4] R. Bhatia, Matrix Analysis, Springer Verlag, 1997.

[5] R. BHATIA AND C. DAVIS, A Cauchy-Schwarz inequality for operators with applications, Linear Alg. Appl 223 (1995), 119-129.

[6] J. I. FujII, M. FujII, T. FurUtA AND R. NAKAMOTO, Norm inequalities equivalent to Heinz inequality, Proc. Amer. Math. Soc. 118 (1993), 827-830.

[7] M. FujII AND T. FurutA, Löwner-Heinz, Cordes and Heinz-Kato inequalities, Math. Japon. 38 (1993), $73-78$.

[8] T. FuRUTA, Norm inequalities equivalent to Löwner-Heinz theorem, Reviews in Math. Phys. 1 (1989), $135-137$.

[9] R. A. HORN AND C. R, JOHNSON, Hadamard and conventional submultiplicativity for unitary invariant norms on matrices, Linear Multilin. Alg. 20 (1987), 91-106.

[10] F. KuBo And T. Ando, Means of positive linear operators, Math. Ann. 246 (1980), 205-224.

[11] M. K. Kwong, Some results on monotone matrix functions, Linear Alg. Appli. 118 (1989), $129-153$.

[12] E. H. LIEB, Convex trace functions and the Wigner-Yanasse-Dyson conjecture, Avances in Math. 11 (1973), 267-288.

[13] W. PUSZ AND S. L. WORONOWICZ, Functional calculus for sesquilinear forms and the purification map, Rep. Math. Phys. 8 (1975), 159-170. 